\title{
Optimization of the Water and Fertilizer of Rice in the Cold Field and the Biochar Application Amount Based on RAGA Model
}

\author{
Y. Li $*(* * *)(* * * *), \mathbf{S} . \mathbf{Y i} *(* * *)(* * * *) \dagger$, Y. Lin**(***)(****) and S. Liu**(***)(****) \\ *College of Engineering, Heilongjiang Bayi Agricultural University, Daqing 163319, China \\ **College of Civil Engineering and Water Conservancy, Heilongjiang Bayi Agricultural University, Daqing 163319, China \\ ***Engineering Research Center of Processing and Utilization of Grain By-products, Ministry of Education, Daqing, \\ 163319, China \\ ****Heilongjiang Engineering Technology Research Center for Rice Ecological Seedlings Device and Whole Process \\ Mechanization,Daqing, 163319, China \\ †Corresponding author: Shujuan Yi; yishujuan_2005@yeah.net
}

Nat. Env. \& Poll. Tech.

Website: www.neptjournal.com

Received: 10-08-2020

Revised: 09-09-2020

Accepted: 09-10-2020

\section{Key Words:}

RAGA model

Cold rice

Water use efficiency

Comprehensive warming

potential

\begin{abstract}
This paper proposes an optimization method based on the RAGA model. Taking rice from a cold area as the research object, this article selects irrigation volume, nitrogen application volume, and biochar application volume as experimental factors, and rice yield, water use efficiency, greenhouse gas emission comprehensive warming potential as influencing indicators. The research design is D311 Field trials by 3 factors of 5 levels of saturation. Hence, we can obtain the data on rice yield, water use efficiency, greenhouse gas emissions and comprehensive warming potential under different levels of water and fertilizer, and biochar application, and regression equations were established respectively. The RAGA model was used to simulate the regression equations. The optimal combination of water and fertilizer, and biochar was obtained as follows: irrigation amount is $7230 \mathrm{~m}^{3} \cdot \mathrm{hm}^{-2}$, nitrogen fertilizer application amount is $92.13 \mathrm{~kg} \cdot \mathrm{hm}^{-2}$, and biochar application amount is $30 \mathrm{t} . \mathrm{hm}^{-2}$. The optimal rice yield obtained under this combination is $9452.20 \mathrm{~kg} \cdot \mathrm{hm}^{-2}$. The water use efficiency is $1.94 \mathrm{~kg} \cdot \mathrm{m}^{-3}$, and the comprehensive warming potential of greenhouse gas emissions is $4546.73 \mathrm{~kg} \cdot \mathrm{hm}^{-2}$. The combined application of water and fertilizer, and biochar optimized by this model can provide a theoretical basis for achieving high yield, water-saving, and emission reduction of rice in cold areas, and it can also provide a reliable calculation method and idea for solving similar optimization problems in the field of agricultural production.
\end{abstract}

\section{INTRODUCTION}

Due to the good taste of rice in black soil in cold areas, the area of rice fields in Northeastern China has increased rapidly in the past ten years (Wang \& Come 2010). The rational combination of irrigation, fertilizer, and biochar is the key to increasing crop yield and water use efficiency and reducing greenhouse gas emissions (Sun et al. 2009, Frolking et al. 2002, Wang et al. 2008). However, in the process of rice growth, there are problems such as extensive irrigation and uneven rainfall, resulting in rice water consumption accounting for more than $90 \%$ of agricultural water. At present, the average irrigation quota in my country is $9000 \mathrm{~m}^{3} \cdot \mathrm{hm}^{-2}$, and the water use efficiency is less than $1 \mathrm{~kg} . \mathrm{m}^{-3}$, which is less than half of that in developed countries (Li et al. 2013).

According to statistics, the current application rate of chemical fertilizers on arable land in my country is close to $400 \mathrm{~kg} \cdot \mathrm{hm}^{-2}$, which is seriously exceeding the safety limit of $225 \mathrm{~kg} \cdot \mathrm{hm}^{-2}$ set internationally for the prevention and control of air and water pollution (Rao et al. 2011, Mao 2009). A long-term unreasonable application of fertilizers will cause crop lodging, white seedlings, weak nitrogen fixation capacity, and a sudden increase in greenhouse gas emissions. Biochar has the characteristics of high carbon content, hard to decompose, high specific surface area, and is loose and porous. The use of biochar can improve the soil's physical and chemical properties and microbiological properties of rice fields, which reduce greenhouse gas emissions (Chen et al. 2014, Liu et al. 2013, Zhou et al. 2017). Therefore, the establishment and perfection of a theoretical system explain the relationship between crop yields, water use efficiency, greenhouse gas emissions and water and fertilizer, and biochar, and the construction of a multi-objective mathematical model finds the best combination to ensure national food security. The major issues facing the implementation of the sustainable agricultural development strategy are using the best combination of irrigation, fertilization, and biochar for agricultural production activities to ensure crop yields, 
save agricultural production resources, reduce agricultural non-point source pollution, improve the ecological environment, and enhance crops quality, which is very significant (Muoneke et al. 2007).

At present, domestic and foreign research reports on the relationship between high yield, water-saving, emission reduction, water and fertilizer, and biochar, mostly adopt orthogonal or orthogonal rotating experimental design methods to design experimental plans, obtain data relationships corresponding to different combinations, use least two multiplying parameter estimation, and establishing nonlinear equations between targets and factors. Then regression analysis method, variance analysis method, single factor effect method, main effect and interaction effect method used to analyze the test results, and find out the best water fertilizer and biochar combined application program (Li et al. 2004, Ai \& Li 2005, Shapiro \&Wortmann 2006, Widdicomde \&Thelen 2002, Cox \& Cherney 2001, Cox et al. 2006). However, this method has shortcomings such as large errors, high difficulty in multivariate replacement, and poor processing capability of sample data with noise. In the process of agricultural production, crop growth is interactively affected by a variety of factors. The factors and indicators have strong nonlinear and black box characteristics. It is difficult to quantitatively describe the causal relationship between them with traditional analysis methods (Zhang et al. 2003). The current research based on the RAGA model can successfully deal with complex problems such as high-dimensionality, multi-peak, nonlinearity, discontinuity, non-convexity, noise, and so on. Then the optimal combination is obtained, which is gradually becoming one of the best tools for solving complex problems. It has been widely used in hydrology, meteorology, geology, economy, medicine, machinery, humanities, etc. (Howell 2009, Zhang et al. 2017, Zhu et al. 2015).

This paper takes rice from a cold area as the research object, and conducts field experiments according to the saturated D311 (Xu 1997) test plan to obtain data on yield, water use efficiency, and greenhouse gas comprehensive warming potential under different water and fertilizer, and biochar combinations, and establish a multi-objective regression equation. An optimization algorithm based on RAGA is proposed for multi-objective optimization, to find the optimal water and fertilizer, and biochar application plan, to provide a reference field management technology for high yield, water-saving, and emission reduction of rice in the northeast cold region.

\section{MATERIALS AND METHODS}

\section{Overview of the Test Area}

The experiment was conducted at the National Rice Irrigation
Test Center Station $\left(125^{\circ} 44^{\prime} \mathrm{E}, 45^{\circ} 63^{\prime} \mathrm{N}\right)$ in Heping Town, Qing'an County, Suihua City, Heilongjiang Province from May to October 2019, which has typical black soil in a cold area. The annual mean temperature is $2.5^{\circ} \mathrm{C}$, the annual mean precipitation reached $550 \mathrm{~mm}$, and the annual mean water surface evaporation was $750 \mathrm{~mm}$. The crop has a hydrothermal growth period of 156 to 171 days and a frost-free period of 128 days throughout the year. The climate is characterized by a cold temperate continental monsoon climate. The soil type is albic soil rice field, with a bulk density of $1.01 \mathrm{~g} . \mathrm{cm}^{-3}$ and a porosity of $61.8 \%$. Basic physical and chemical properties of soil include organic matter mass ratio $41.4 \mathrm{~g} . \mathrm{kg}^{-1}$, $\mathrm{pH}$ value 6.40 , total nitrogen mass ratio $15.06 \mathrm{~g} . \mathrm{kg}^{-1}$, total phosphorus mass ratio 15.23 g. $\mathrm{kg}^{-1}$, total potassium mass ratio 20.11 g. $\mathrm{kg}^{-1}$, alkaline hydrolysis nitrogen mass ratio $154.36 \mathrm{mg} . \mathrm{kg}^{-1}$, effective phosphorus mass ratio $25.33 \mathrm{mg}$. $\mathrm{kg}^{-1}$ and available potassium mass ratio $157.25 \mathrm{mg} \cdot \mathrm{kg}^{-1}$.

\section{Experimental Design and Process}

The test adopts the optimal design of saturated D311. The test factors are irrigation amount, nitrogen fertilizer, and biochar. The specific application amount is as follows: the irrigation amount is $5000 \sim 10000 \mathrm{~kg} \cdot \mathrm{hm}^{-2}$, nitrogen fertilizer (pure nitrogen) is 50 150kg.hm ${ }^{-2}$, and biochar is $0 \sim 40 \mathrm{t} . \mathrm{hm}^{-2}$. The experimental design scheme is shown in Table 1.

The experiment set up 11 treatments, repeated 3 times and arranged in random blocks. Each block has an area of $10 \mathrm{~m} \times 10 \mathrm{~m}=100 \mathrm{~m}^{2}$. Rice is planted around the block to add protection rows. The technical measures such as rice seedling raising, transplanting, plant protection, and medication, as well as field management conditions are the same. To reduce the influence of lateral penetration on the test, the isolation treatment is adopted among the plots, that is, plastic boards and cement ridges are used as the barriers around the plots. Materials are buried in the field $40 \mathrm{~cm}$ deep below the ground surface. The irrigation method adopts a pipeline water supply, and each pipeline is equipped with a water meter to control the amount of irrigation. Nitrogen fertilizer is applied according to the ratio of base fertilizer, tiller fertilizer, and ear fertilizer at 5:3:2. P-fertilizer is used as base fertilizer at one time, and the amount of application is $45 \mathrm{~kg} . \mathrm{hm}^{-2}$. K-fertilizer is divided into basal fertilizer and 8.5 leaf age (young ear differentiation period), the front and the back ratio is $1: 1$, the application rate is $80 \mathrm{~kg} \cdot \mathrm{hm}^{-2}$. Biochar is applied to the surface of the soil, and the biochar is used with the rotary tiller. Layers of soil are evenly mixed. The tested fertilizers were urea ( $\mathrm{N}$ content is $46 \%$ ), diammonium phosphate ( $\mathrm{N}$ content is $18 \%, \mathrm{P}_{2} \mathrm{O}_{5}$ content is a $46 \%$ ), potash fertilizer $\left(\mathrm{K}_{2} \mathrm{O}\right.$ content is $\left.40 \%\right)$, and the tested biochar was a straw biochar product of Liaoning Jinhefu Agricultural Development Co. Ltd. 
Table 1: Saturated D-311 optimal design processing table.

\begin{tabular}{|c|c|c|c|c|c|c|c|}
\hline \multirow{2}{*}{$\begin{array}{l}\text { Treatment } \\
\text { number }\end{array}$} & \multicolumn{3}{|c|}{ Coded value } & \multicolumn{3}{|l|}{ Actual value } & \multirow{2}{*}{$\begin{array}{l}\text { GWP } \\
\left(\mathrm{kg} \cdot \mathrm{hm}^{-2}\right)\end{array}$} \\
\hline & $\mathrm{X}_{1}$ & $\mathrm{X}_{2}$ & $\mathrm{X}_{3}$ & $\mathrm{~W}\left(\mathrm{~m}^{3} \cdot \mathrm{hm}^{-2}\right)$ & $\mathrm{N}\left(\mathrm{kg} \cdot \mathrm{hm}^{-2}\right)$ & $\mathrm{BC}\left(\mathrm{t} . \mathrm{hm}^{-2}\right)$ & \\
\hline 1 & 0 & 0 & 2 & 5000 & 100 & 40 & 3450.11 \\
\hline 2 & 0 & 0 & -2 & 5000 & 100 & 0 & 5955.66 \\
\hline 3 & -1.414 & -1.414 & 1 & 3200 & 65 & 30 & 5119.64 \\
\hline 4 & 1.414 & -1.414 & 1 & 6800 & 65 & 30 & 5098.78 \\
\hline 5 & -1.414 & 1.414 & 1 & 3200 & 135 & 30 & 4593.49 \\
\hline 6 & 1.414 & 1.414 & 1 & 6800 & 135 & 30 & 4377.51 \\
\hline 7 & 2 & 0 & -1 & 7500 & 100 & 10 & 4731.18 \\
\hline 8 & -2 & 0 & -1 & 2500 & 100 & 10 & 4269.39 \\
\hline 9 & 0 & 2 & -1 & 5000 & 150 & 10 & 4782.40 \\
\hline 10 & 0 & -2 & -1 & 5000 & 50 & 10 & 5087.59 \\
\hline 11 & 0 & 0 & 0 & 5000 & 100 & 20 & 4133.44 \\
\hline
\end{tabular}

The tested rice variety was Longqingdao No. 3, the local main cultivars, with a planting density of 4 plants per hole. Base fertilizer was applied on May 6, transplanted on May 17, and tillering fertilizer was applied on May 31 and Panicle fertilizer was applied on July 19. Ear fertilizer harvested on September 20. The growth period of rice is 127 days, which is divided into the returning green stage (May 17 to May 30), the tillering period (May 31 to July 7), the jointing-booting stage (July 8 to July 25), heading date (July 26 to August 4), milky maturity (August 5 to August 24), and yellow ripening stage (August 25 to September 20).

\section{Test Index Determination}

Yield: This test observes the number of productive ears, the number of rows per ear, the thousand-grain weight, and the seed-setting rate of each treatment to calculate the theoretical yield. Theoretical yield $=$ effective panicle number $\times$ grain number per panicle $\times$ thousand-grain weight $\times$ seed setting rate.

Water consumption: Accurately record the irrigation time and amount of each treatment through the water meter, and observe the changes of the water surface scale every day. At the same time, observe the reference crop water demand.

Greenhouse Gas: The sampling of flue gases was carried out on sunny days, which adopts the static chamber/gas chromatogram. When sampling, a syringe was used to extract about $100 \mathrm{~mL}$ of gas from the box, collect samples at 0,5 , 10 , and 15 minutes respectively, then the gas in the syringe was immediately transferred to the aluminum foil sampling bag, and the sampling bag was brought back to the laboratory for measurement in time. The gas concentration is detected by Shimadzu GC-14B gas chromatograph, and the standard gas is provided by the National Standard Material Center.

\section{Calculation Method and Data Analysis}

Water use efficiency: Water use efficiency calculation formula:

$$
\mathrm{WUE}=\mathrm{Y} / \mathrm{ETc}
$$

Where WUE is water use efficiency, $\mathrm{Y}$ is yield, ETc is water consumption

Greenhouse gas emissions: The formula for calculating greenhouse gas emission flux from rice fields (Zheng et al. 1998): $\mathrm{F}=\rho \cdot h \cdot d c / d t \cdot 273 /(273+\mathrm{T})$.

Among them, $\mathrm{F}$ is the gas emission flux $\left(\mathrm{mg} \cdot \mathrm{m}^{-2} \cdot \mathrm{h}^{-1}\right), \rho$ is the gas density under standard conditions $\left(\mathrm{kg} \cdot \mathrm{m}^{-3}\right), \mathrm{h}$ is the box height $(\mathrm{m})$, and $\mathrm{dc} / \mathrm{dt}$ is the inside of the sampling box. The concentration change rate of the gas is $\left(\mathrm{mL} \cdot \mathrm{m}^{-}\right.$ $\left.{ }^{3} \cdot \mathrm{h}^{-1}\right), 273$ is the gas equation constant, and T is the average temperature $\left({ }^{\circ} \mathrm{C}\right)$ in the sampling box during the sampling process. Calculate the gas emission flux according to the relationship curve of the gas sample concentration and time. The emission during the growth season is the product of the average flux value of each growth period and the total length of the growth period and then accumulated.

In this study, the global warming potential GWP (the GWP of $\mathrm{CO}_{2}$ is 1 ) is used to express the relative radiation effect of different greenhouse gases of the same quality on the greenhouse effect enhancement. Taking 100a as the time scale, the GWP of $\mathrm{CH}_{4}$ and $\mathrm{N}_{2} \mathrm{O}$ per unit mass are 21 and 310 times that of $\mathrm{CO}_{2}$ respectively (Nie et al. 2019). The calculation formula of GWP is as follows: 


$$
G W P=f C H_{4} \times 21+f N_{2} O \times 310
$$

In the formula, $f$ is the emission of different greenhouse gases in the rice field ecosystem during the whole growth period of rice.

Data Analysis: The test data are analyzed and calculated using Excel2003, SPSS17.0 and MATLAB7.0.

\section{Introduction and Construction of RAGA Model}

\section{Introduction to the RAGA Model}

The RAGA model is an accelerated genetic algorithm model based on real number coding (Jin et al. 2001), overcomes the shortcomings of traditional genetic algorithms (GA). This paper adopts real number coding. It can search a larger space and can be mixed with other classic optimization algorithms to facilitate the processing of complex decisions. Variable constraint conditions by order-based evaluation function model are used to evaluate the individual fitness value, so that is not affected by the actual target value. In the evolutionary iteration, the parallel calculation of the genetic algorithm is realized, and all the offsprings are evaluated uniformly, to ensure the superiority of understanding as much as possible, further accelerate the evolution time, and gradually adjust the search space of optimized variables, and the algorithm optimization speed is greatly improved, which speeds up the convergence speed. The principle is as follows.

$$
\min f=\sum_{i=1}^{n} \| F\left(C, X_{i}-Y_{i} \|^{q}\right.
$$

Where: $\mathrm{C}=[\mathrm{Ci}]$ is the model $\mathrm{p}$ variables (parameters) to be optimized. $\left[a_{j}, b_{j}\right]$ is the initial change interval (search interval) of $c_{i}$. $\mathrm{X}$ is the $\mathrm{N}$-dimensional input variable of the model. $\mathrm{Y}$ is the $\mathrm{M}$-dimensional yield vector of the model. $\mathrm{F}$ is the nonlinear model, namely F: $R^{N} \rightarrow R^{M} .\left\{\left(\mathrm{X}_{\mathrm{i}}, Y_{\mathrm{i}}\right) \mid \mathrm{i}=1,2, \cdots \mathrm{m}\right\}$ is the input and yield by $\mathrm{m}$ sets of data for the model. \|\| is the norm. $\mathrm{q}$ is a real number. When $\mathrm{q}=1$, it is a linear function criterion, and when $\mathrm{q}=2$, it is a quadratic function criterion, which may be determined by specific modeling requirements. $f$ is the optimization function criterion.

\section{RAGA Model Construction}

This study takes minimization as an example.

$$
\begin{gathered}
\min f(x) \\
\text { s.t } a(\mathrm{j}) \leq \mathrm{x}(\mathrm{j}) \leq \mathrm{b}(\mathrm{j})
\end{gathered}
$$

Step 1: Real-number the variables. The following linear transformation is used as follows.

$$
X(j)=a(j)+y(j)[b(j)-a(j)],(j=1,2, \ldots p) \ldots(5)
$$

In the formula, $a(j)$ and $b(j)$ are the initial variables. $y(j)$ is the $j$ th variable $x(j)$ to be optimized on $a(j), b(j)$ corresponds to a real number in the interval $[0,1]$, that is, the genetic gene in RAGA. At this time, the genes corresponding to all variables are connected together to form the coding form of the problem solution, which is called a chromosome, [y(1), $\mathrm{y}(2) \ldots \mathrm{y}(\mathrm{p})]$.

Step 2: Initialize the parent population. Suppose the parent population is $n$, randomly generate random numbers between $\mathrm{n}$ groups $[0,1]$, each group has $\mathrm{p}$, that is $\{u(j, i)\}(j=1,2 \ldots p ; i=1,2 \ldots n), u(i, j)$ will be the parent individual value of the initial population $y(j, i)$. The optimized variable $x(j, i)$ can be obtained by formula (7-17), and the corresponding objective function value can be obtained by formula (7-15). The corresponding individual $f(i)$ will be sorted from small to large. The value $\{f(i)(i=1,2 \ldots n)\}$ of the objective function is smaller, the individual's adaptability is stronger. After sorting, the first $\mathrm{k}$ individuals are selected as excellent individuals and directly enter the next generation.

Step 3: Evaluation of the fitness of the parent population. A certain probability is set for each chromosome $y(j, i)$ in the population so that it will be selected in a certain proportion. The adaptability of the chromosomes is stronger, the possibility of being selected greater. In this paper, we choose an evaluation function based on order (represented by eval $[y(j, i)])$. The idea is to use the order of chromosomes to make random combinations instead of based on the target value, and its evaluation function is as follows:

$$
\mathrm{e} v a l[y(j, i)]=\alpha(1-\alpha)^{i-1}
$$

Where $\alpha$ is a random number between $(0,1)$. When $\mathrm{i}=1$, it means the chromosome is the best, and when $\mathrm{i}=\mathrm{n}$, the chromosome is the worst.

Step 4: Choose. The selection process is based on the principle of rotating the gambling wheel, defining $n$ times as the basis, and one rotation will generate a new chromosome. The gambling wheel selects chromosomes based on the fitness of each individual. The process is as follows:

$$
\begin{aligned}
& q_{0}=0 \\
& q_{i}=\sum_{j=1}^{i} \operatorname{eval}[y(j, i)](j=1,2 \ldots p ; i=1,2 \ldots n) \\
& q_{i-1} \leq r \leq q_{i} \\
& r \in\left[0, q_{i}\right]
\end{aligned}
$$

Repeat step 2 and step 3 for $\mathrm{n}$ times, so that $\mathrm{n}$ duplicate chromosomes can be obtained to form a new generation of individuals.

Step 5: Hybridization operation. First, select the cross probability $\mathrm{p}_{\mathrm{c}}$, then there are a total of chromosomes $p_{\mathrm{m}} \cdot n$ 
in the population for crossover operation. If $r \leq p c$, choose $y(j, i)$ as a parent and pair them randomly: [y1'(j,i), y2'(j,i)], [y3'(j,i) , y4'(j,i)], [y5'(j,i), y6'(j,i)]. To ensure their pairwise pairing, when the parent individual has an odd number, one chromosome can be increased or decreased. The crossover adopts the arithmetic crossover method, and the specific algorithm is as follows:

$x=c y_{1}^{\prime}(j, i)+(1-c) y_{2}^{\prime}(j, i) ; y=(1-c) y_{1}^{\prime}(j, i)+c y_{2}^{\prime}(j, i)$

Where: $\mathrm{c}$ is a random number between $(0,1)$.

If the calculated solution set is convex, it is guaranteed that the two offspring are feasible. If it is not a convex set, the feasibility of the offspring must be verified at this time. If the two offspring are feasible, they can be used instead of the parent to produce a new one. With a random number ' $c$ ', repeat the crossover operation until a new viable offspring is obtained. This process only replaces the parent with a viable offspring. If a new generation of individuals is not feasible, some correction methods must be adopted to make it a viable chromosome.

From $\mathrm{i}=1$ to $\mathrm{n}$, repeat step 5 to obtain a new generation of population $\{y 2(j, i)\}(j=1,2 \ldots p ; i=1,2 \ldots n)$ through the hybridization operation.

Step 6: Mutation operation. The mutation process is similar to the hybridization process. The mutation probability $\mathrm{p}_{\mathrm{m}}$ is selected, that is $p_{\mathrm{m}} \cdot n_{\text {so that there will be chromosomes }}$ in the population for mutation operation. If $r \leq p m$, select $y(j$, i) as the parent of the mutation, and use $y 3^{\prime}(\mathrm{j}, \mathrm{i})$ for each selected parent. The expression is as follows.

$$
\mathrm{y}_{3}(j, i)=y_{3}(j, i)+\operatorname{Md}(i=1,2, \ldots p)
$$

In the formula, $\mathrm{M}$ is a random number between $(0, \mathrm{M})$, and $\mathrm{d}$ is the randomly selected variation direction in $\mathrm{R}^{\mathrm{n}}$. If no feasible solution is found in the predetermined number of cycles, set $\mathrm{M}=0$ and restart the calculation.

From $i=1$ to $n$, step 6 is repeated to get a new generation of population after mutation

$$
\left\{y_{3}(j, i\}=\{j=1,2 \ldots p ; i=1,2 \ldots n\}\right.
$$

Step 7: Iterative evolution. The $3 \mathrm{n}$ offspring individuals obtained through step 4 to step 6 are sorted according to their fitness function values from large to small, and the previous (n- k) offspring individuals are selected as the new parent population. Then proceed to the next round of optimization process, repeat step 3 , re-evaluate, select, cross, and mutate the parent individuals.

Step 8: Speed up processing. Because too many evolution times may lead to the weakening of the algorithm's optimization ability, the new outstanding individuals produced by the first and second evolutions are taken as the new change space for the next optimization, and the above step 1 to step 7 are repeated to speed up. The range of excellent individuals will gradually shrink and get closer to the optimal value until the program reaches a certain preset number of times or the objective function value is less than the preset value. At this time, the algorithm ends. The result comes from the above steps by the optimized current optimal individual.

\section{RESULTS AND DISCUSSION}

\section{The Establishment of Multi-Objective Regression Equation}

According to the test plan, the test data of production, water use efficiency, and greenhouse gas comprehensive warming potential indicators are shown in Table 2.

Taking $X_{1}(W), X_{2}(N), X_{3}(C)$ coding values as independent variables, and the yield, water use efficiency, and greenhouse gas comprehensive warming potential are shown in Table 2 as dependent variables A quadratic polynomial regression analysis is carried out to obtain the regression equation of the target:

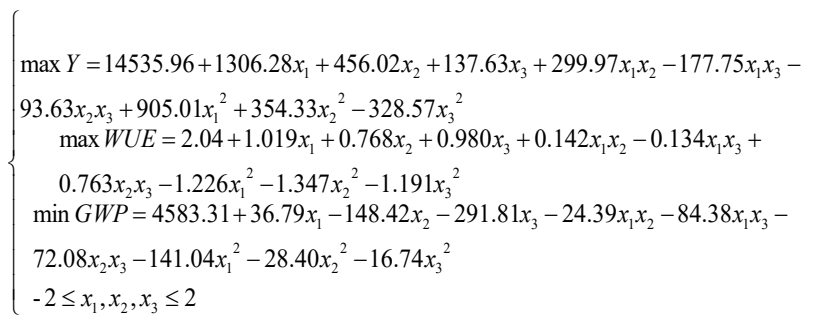

Perform $\mathrm{F}$ test on each regression equation: $\left(\mathrm{F}_{\mathrm{Y}}=5.37\right.$, $\left.\mathrm{F}_{\mathrm{WUE}}=4.75, \mathrm{~F}_{\mathrm{GWP}}=144.48\right)>\left(\mathrm{F}_{0.01}(10,20)=3.37\right)$, indicating that the relationship between the regression equation is extremely significant, that is, the regression equation can reflect the relationship between each target and the relationship between irrigation volume, nitrogen fertilizer and biochar. The $t$-test was performed on the regression coefficients in each target regression equation, $\mathrm{t}_{\mathrm{i}}>\mathrm{t}_{0.05}(11)=1.796$, indicating that the influence of each factor on the index was significant.

Optimal Combination of Yield, Water Use Efficiency, and Greenhouse Gas Comprehensive Warming Potential Based on RAGA Model

This article uses the RAGA model steps 1 to 8 to optimize the formula (10) and calculates the optimal solution of the above-mentioned multi-objective optimization problem. In this article, the initial number of individuals is set to 1200 , 
Table 2: Experimental treatment data of different water and fertilizers, and biochar.

\begin{tabular}{|c|c|c|c|c|c|c|c|c|c|}
\hline \multirow{2}{*}{$\begin{array}{l}\text { Treatment } \\
\text { number }\end{array}$} & \multicolumn{3}{|c|}{ Coded value } & \multicolumn{3}{|c|}{ Actual value } & \multirow{2}{*}{$\begin{array}{l}\mathrm{Y} \\
\left(\mathrm{kg} / \mathrm{hm}^{2}\right)\end{array}$} & \multirow{2}{*}{$\begin{array}{l}\text { WUE } \\
\left(\mathrm{kg} / \mathrm{m}^{3}\right)\end{array}$} & \multirow{2}{*}{$\begin{array}{l}\mathrm{GWP} \\
\left(\mathrm{kg} / \mathrm{hm}^{2}\right)\end{array}$} \\
\hline & $\mathrm{X} 1$ & $\mathrm{X} 2$ & $\mathrm{X}_{3}$ & $\mathrm{~W}\left(\mathrm{~m}^{3} / \mathrm{hm}^{2}\right)$ & $\mathrm{N}\left(\mathrm{kg} / \mathrm{hm}^{2}\right)$ & $\mathrm{BC}\left(\mathrm{t} / \mathrm{hm}^{2}\right)$ & & & \\
\hline 1 & 0 & 0 & 2 & 5000 & 100 & 40 & 7187.72 & 1.88 & 3450.11 \\
\hline 2 & 0 & 0 & -2 & 5000 & 100 & 0 & 9086.00 & 1.68 & 5955.66 \\
\hline 3 & -1.414 & -1.414 & 1 & 3200 & 65 & 30 & 8462.00 & 1.57 & 5119.64 \\
\hline 4 & 1.414 & -1.414 & 1 & 6800 & 65 & 30 & 9213.00 & 1.92 & 5098.78 \\
\hline 5 & -1.414 & 1.414 & 1 & 3200 & 135 & 30 & 8202.65 & 1.54 & 4593.49 \\
\hline 6 & 1.414 & 1.414 & 1 & 6800 & 135 & 30 & 8259.44 & 2.04 & 4377.51 \\
\hline 7 & 2 & 0 & -1 & 7500 & 100 & 10 & 6065.62 & 1.96 & 4731.18 \\
\hline 8 & -2 & 0 & -1 & 2500 & 100 & 10 & 8025.00 & 1.73 & 4269.39 \\
\hline 9 & 0 & 2 & -1 & 5000 & 150 & 10 & 9500.00 & 1.80 & 4782.4 \\
\hline 10 & 0 & -2 & -1 & 5000 & 50 & 10 & 14535.96 & 1.66 & 5087.59 \\
\hline 11 & 0 & 0 & 0 & 5000 & 100 & 20 & 9020.00 & 1.95 & 4133.44 \\
\hline
\end{tabular}

the maximum genetic algebra is 60 , and the binary number of variables is 20 . The crossover probability is taken as 0.7 . The yield (Y), water use efficiency (WUE), greenhouse gas comprehensive warming potential (GWP), and the curve of the overall model with the number of iterations are shown in Fig. 1.

It can be seen from Fig. 1 that each curve has a larger amplitude when the number of iterations is small. The comprehensive temperature increase trend and the overall model curve decline rapidly at the beginning of the iteration, which stabilizes after the iteration number reaches a certain value. The yield and water use efficiency curve presents an up and down trend, and the yield curve is more stable than the water use efficiency curve. The final optimal yield is 9452.20 $\mathrm{kg} . \mathrm{hm}^{-2}$, the optimal water use efficiency is $1.94 \mathrm{~kg} \cdot \mathrm{m}^{-3}$, and the optimal warming potential is $4546.73 \mathrm{~kg} \cdot \mathrm{hm}^{-2}$. The coded value of water is 1.784 when the optimal solution is obtained, the coded value of nitrogen fertilizer is 1.685 , and the coded value of biochar is 1.0, and the actual value is converted into irrigation amount is $7230 \mathrm{~m}^{3} \cdot \mathrm{hm}^{-2}$, nitrogen

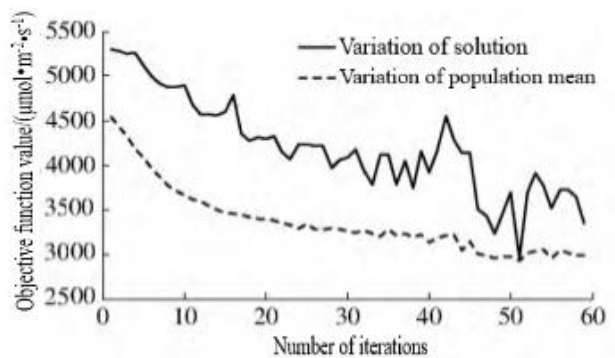

(a) GWP

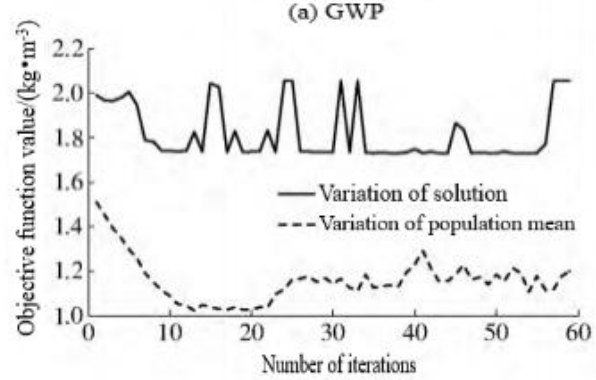

(c) WUE

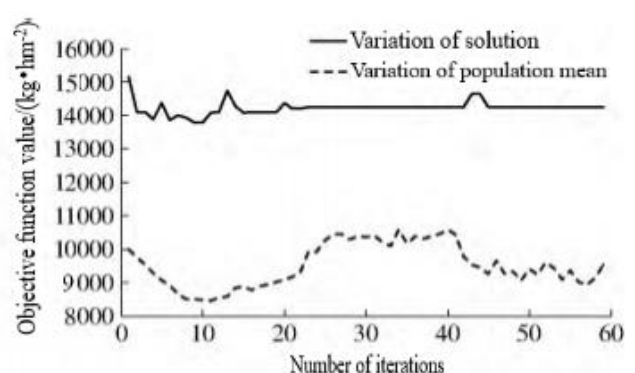

(b) Yield

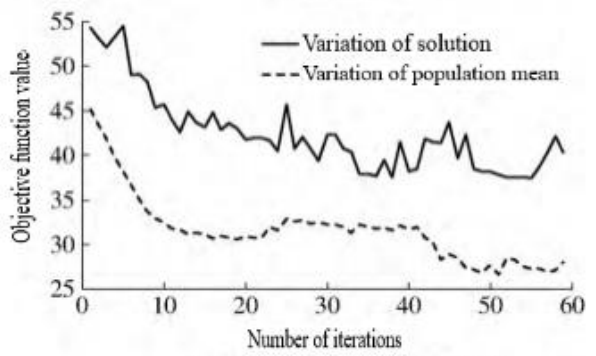

(d) Sum of three objective functions

Fig.1: GWP, Yield, Water use efficiency, and the optimal solution of the whole model and performance tracking. 
fertilizer application amount is $92.13 \mathrm{~kg} \cdot \mathrm{hm}^{-2}$, and biochar application amount is $30 \mathrm{t} \cdot \mathrm{hm}^{-2}$.

\section{CONCLUSION}

Based on the traditional regression equation fitting, this paper proposes an optimization method based on the RAGA model and applies it to the practical problem of irrigation, fertilization, and biochar optimization in rice planting and production in cold areas, which expands the RAGA model Application scope.

RAGA algorithm proposed in this paper is used to optimize the experimental data of rice water and fertilizer, and biochar in cold areas. The rice yield under the experimental conditions is $9452.20 \mathrm{~kg} \cdot \mathrm{hm}^{-2}$, the water use efficiency is $1.94 \mathrm{~kg} \cdot \mathrm{m}^{-3}$, the greenhouse gas emission comprehensive warming potential is $4456.73 \mathrm{~kg} \cdot \mathrm{hm}^{-2}$, the corresponding irrigation amount is $7230 \mathrm{~m}^{3} \cdot \mathrm{hm}^{-2}$, the amount of nitrogen fertilizer application is $92.13 \mathrm{~kg} \cdot \mathrm{hm}^{-2}$, and the amount of biochar application is $30 \mathrm{t}$. $\mathrm{hm}^{-2}$. This method can provide a theoretical basis for increasing production, saving water, and reducing emissions in the process of rice production in cold areas.

The application of the optimization method based on the RAGA model in the optimization of rice irrigation, fertilization, and biochar application amount has important theoretical and practical significance for guiding the production of rice in cold areas, increasing rice yield, reducing production water consumption, and reducing agricultural non-point source pollution. At the same time, it provides a reliable calculation method and idea for solving similar multi-objective complexity optimization problems in the field of agricultural production.

\section{ACKNOWLEDGMENTS}

This work was supported by Heilongjiang Bayi Agricultural University Support Program for San Heng San Zong (TDJH201803), Engineering Research Center of Processing and Utilization of Grain By-products, Ministry of Education, Heilongjiang Engineering Technology Research Center for Rice Ecological Seedlings Device and Whole Process Mechanization.

\section{REFERENCES}

Ai, F.Q. and Li, G.Z. 2005. Rotating regression analysis of the relationship between nitrogen application rate, density, and rape yield. Chinese Agric. Sci. Bull., 21(4): 142-144.

Chen, W.F., Zhang, W.M. and Meng, J. 2014. Review and prospects of research on biochar and agricultural environment. J. Agric. Environ. Sci., 33(5): 821-828.
Cox, W.J. and Cherney, D.J.R. 2001. Row spacing, plant density, and nitrogen effects on corn silage. Agro. J., 93(3): 597-602.

Cox, W.J., Hanchar, J.J. and Knoblauch, W.A. 2006. Growth, yield, quality, and economics of corn silage under different row spacing. Agro. J., 98(1): 163-167.

Frolking, S., Qiu J. and Boles S. 2002. Combing remote sensing and ground census data to develop new maps of the distribution of rice agriculture in China. Global Biogeochem Cyc., 16: 1091-1101.

Howell, T.A. 2009. Relationship between crop production and transpiration, evapotranspiration, and irrigation. Irrig. Agric. Crop Agro. Monog., 30: 292-427.

Jin, J.L., Yang, X.H. and Ding, J. 2001. Improved scheme of standard genetic algorithm-accelerated genetic algorithm. Sys. Eng. Theory Pract., (4): 8-13.

Li, G.Z., Ai, F.Q. and Zhao, Y.H. 2004. The effect of different densities and nitrogen fertilizers on rape yield. J. Mount. Agric. Biol., 23(3): 198-201.

Liu, Y.X., Wang, Y.F. and Lu, H.H. 2013. Effects of biomass carbonization on rice field greenhouse gas emissions and soil physical and chemical properties. J. Appl. Ecol., 24(8): 2166-2172.

Mao, Z. 2009. Construct water-saving and anti-pollution ecological irrigation area. China Water Resour., (19): 28.

Muoneke, C.O., Ogwuche, M.A.O. and Kalu, B.A. 2007. Effect of maize planting density on the performance of maize/soybean intercropping system in a guinea savannah agroecosystem. Afr. J. Agric. Res., 2(12): 667-677.

Nie, T.Z., Chen, P., and Zhang, Z.X. 2019. Effects of different types of water and nitrogen fertilizer management on greenhouse gas emissions, yield, and water consumption of paddy fields in a cold region of China. Int. J. Environ. Res. Pub. Health, 16: 1639.

Rao, J., Xu, X.Y. and Ji, X.T. 2011. Research on the status, mechanism, and countermeasures of agricultural non-point source pollution in my country. Issues Agric. Eco., (8): 81-82.

Shapiro, C.A. and Wortmann, C.S. 2006. Corn response to nitrogen rate, row spacing, and plant density in Eastern Nebraska. Agro. J., 98(3): 529-535.

Sun, A.H., Zhang, Z.X. and Zhu, S.J. 2009. Experimental study on water consumption law and water use efficiency of rice with different irrigation modes in Sanjiang Plain. Water-Saving Irrig., (11): 12-14.

Wang, Q.J. and Come, Y.C. 2010. On the countermeasures and suggestions for rice production and sustainable utilization of water resources in Heilongjiang Province. China Rice, 16(4): 25-28.

Wang, Y.Y., Chen, W.W. and Zhao Z.C. 2008. $\mathrm{CH}_{4}$ and $\mathrm{N}_{2} \mathrm{O}$ emission characteristics and emission estimation of rice in a cold area in Sanjiang Plain. Trans. Chinese Soc. Agric. Eng., 24(10): 170-176.

Widdicomde, W.D. and Thelen, K.D. 2002. Row width and plant density effects on corn grain production in the Northern corn belt. Agro. J., 94(5): 1020-1023.

Xu, Z.R. 1997. Regression analysis and experimental design. Beijing: China Agric. Press, 1997: 102-143.

Zhang, S.J., He, Y. and Fang, H. 2003. The application of artificial neural networks in the analysis of the relationship between crop yield and soil spatial distribution information. Sys. Eng. Theory Pract., (12): 121-127.

Zhang, Z.X., Zhang, S.W. and Guo, D.D. 2017. Coupling effect analysis of different water and fertilizer conditions on maize and optimal water and fertilizer application scheme. J. Agric. Mach., 48(9): 206-214.

Zheng, X.H., Wang, M.X. and Wang, Y.S. 1998. Comparison of manual and automatic methods for measurement of methane emission from rice paddy fields. Adv. Atmos. Sci., 15(4): 569-579.

Zhou, F., Xu, C.Y. and Wang, Y.L. 2017. The impact of biochar on soil $\mathrm{CH}_{4}$ and $\mathrm{N}_{2} \mathrm{O}$ emissions. Environ.Sci., 38(9): 3831-3839.

Zhu, D.L., Zhan, T. and Zhang, Y. 2015. Multi-neighborhood structure and multi-objective genetic algorithm. Trans. Chinese Soc. Agric. Mach., 46(4): 309-315. 